\title{
Severe brain trauma injury: when no intracranial pressure monitoring is available
}




\title{
Severe brain trauma injury: when no intracranial pressure monitoring is available
}

\author{
Luis Rafael Moscote-Salazar', Guru Dutta Satyarthee ${ }^{2}$, Alexis Rafael \\ Narvaez-Rojas ${ }^{1}$ \\ ${ }^{1}$ Department of Neurosurgery, Researcher, Latin America Foundation of Neurotrauma \& Neuro \\ Critical Care, Red Latino, COLOMBIA \\ ${ }^{2}$ Department of Neurosurgery, Neurosciences Centre, AIIMS, New Delhi, INDIA
}

Brain trauma injury is a major issue in Latin American countries, which has the highest incidence worldwide $(1,2)$ and the lack of economic resources for the treatment of this condition was the ideal setting to prompt discussion on developing cost-effective approaches that may be of benefit not only for the region but around the world, since as the authors pointed out, even in high-income countries (HICs), intracranial pressure monitors are not always available due to cost issues as described in previous articles. (3-6)

By the other hand, the ongoing research on the imaging and clinical exam (ICE) approach may be crucial for the design of future evidence-based guidelines around the world, although in many countries is considered almost illegal not using intracranial pressure monitoring (ICP), the reality is, where are the evidence-based guidelines to manage patients when no ICP monitoring is readily available at the point-of-care? or when transferring from certain areas may be difficult or take a lot of time and may worsen patients' outcomes, especially during a disaster or war times and second, the research methods that can be used even overseas may cause a great impact in the pool of knowledge by gathering experience from many regions at a very cost-effective approach.

Intracranial pressure monitoring, considered to be the standard of care as analyzed in the $4^{\text {th }}$ edition of the Guidelines for the Management of Severe Traumatic Brain Injury (GMSTBI) developed in 2016 (7) in reference to the quality of information on ICP monitoring, one Class 1 study, four class 2 and five class 3 along with four class three studies from the third edition, where in the only class 1 study, ICP showed lower mortality especially in patients $<65$ years of age, (8) found $9.9 \%$ of the variation in mortality across center due to the use of ICP. The studies evaluated in the GMSTBI were observational, the authors suggested that the selection of patients for monitoring could influence importantly the observed outcomes. (7)

Chesnut et al. on the Benchmark Evidence from South American Trials: Treatment of Intracranial Pressure (BEST:TRIP) trial, 
developed a multicenter, parallel-group trial, with randomized assignment to intracranialpressure monitoring (ICP group) or imaging and clinical examination (ICE group) in Bolivia and Ecuador with 324 participants, where the monitoring-based interventional algorithm tested did not show the superiority of ICP use over ICE approach.9 This trial is the most important body of knowledge in this specific subject and a good reason to develop consensus guidelines to manage severe TBI in places where ICP monitoring is unavailable (war/terrorism/disaster/LIC).

In the $21^{\text {st }}$ century, we have multiple software available across-platforms enabling communication via the internet, with almost universal access, by expanding the use of this methods to achieve consensus, we will empower multidisciplinary discussion and eventually improve patient care.

Finally we believe, it can be of important benefit to be evaluated by HIC to provide health-care personnel tools for an emergency where settings may change from what they are used to.

\section{Correspondence}

Luis Rafael Moscote-Salazar, MD, Neurosurgeon. mineurocirujano@aol.com

+16122545285

Address: Facultad de Medicina, Campus de Zaragocilla, Universidad de Cartagena, Cartagena de Indias, Colombia

\section{References}

Hyder AA, Wunderlich CA, Puvanachandra P, Gururaj G, Kobusingye OC. The impact of traumatic brain injuries: a global perspective. NeuroRehabilitation. 2007;22(5):341-353.

http://www.ncbi.nlm.nih.gov/pubmed/18162698.

Accessed December 10, 2017.

2. Roozenbeek B, Maas AIR, Menon DK. Changing patterns in the epidemiology of traumatic brain injury. Nat Rev Neurol. 2013;9(4):231-236. doi:10.1038/nrneurol.2013.22.

3. Stocchetti N, Penny KI, Dearden M, et al. Intensive care management of head-injured patients in Europe: a survey from the European brain injury consortium. Intensive Care Med. 2001;27(2):400-406. http://www.ncbi.nlm.nih.gov/pubmed/11396285.

Accessed December 11, 2017.

4. Sahjpaul R, Girotti M. Intracranial pressure monitoring in severe traumatic brain injury--results of a Canadian survey. Can J Neurol Sci. 2000;27(2):143-147. http://www.ncbi.nlm.nih.gov/pubmed/10830348.

Accessed December 11, 2017.

5. Myburgh JA, Cooper DJ, Finfer SR, et al. Epidemiology and 12-Month Outcomes From Traumatic Brain Injury in Australia and New Zealand. J Trauma Inj Infect Crit Care. 2008;64(4):854-862. doi:10.1097/TA.0b013e3180340e77.

6. Hesdorffer DC, Ghajar J. Marked Improvement in Adherence to Traumatic Brain Injury Guidelines in United States Trauma Centers. J Trauma Inj Infect Crit Care. 2007;63(4):841-848. doi:10.1097/TA.0b013e318123fc21.

7. Carney N, Totten AM, Hawryluk GWJ, et al. Guidelines for the Management of Severe Traumatic Brain Injury 4th 2016. https://braintrauma.org/uploads/03/12/Guidelines_for_ Management_of_Severe_TBI_4th_Edition.pdf. Accessed December 11, 2017.

8. Alali AS, Fowler RA, Mainprize TG, et al. Intracranial Pressure Monitoring in Severe Traumatic Brain Injury: Results from the American College of Surgeons Trauma Quality Improvement Program. J Neurotrauma. 2013;30(20):1737-1746. doi:10.1089/neu.2012.2802.

9. Chesnut RM, Temkin N, Carney N, et al. A Trial of Intracranial-Pressure Monitoring in Traumatic Brain Injury. N Engl J Med. 2012;367(26):2471-2481. doi:10.1056/NEJMoa1207363. 